\title{
Influence of framework Si/Al ratio and topology on electron transfers in zeolites $* \dagger$
}

\author{
Thomas Crémoux ${ }^{1}$, Isabelle Batoneau-Gener ${ }^{2}$, Alain Moissette ${ }^{1}$, Jean-Louis \\ Paillaud $^{3,4}$, Matthieu Hureau ${ }^{1}$, Emanuelle Lignier ${ }^{3,4}$, Claudia Morais ${ }^{2}$, Sébastien \\ Laforge $^{2}$, Claire Marichal ${ }^{3,4}$, and Habiba Nouali ${ }^{3,4}$
}

\author{
${ }^{1}$ LASIR, Université de Lille, Villeneuve d'Ascq 59655, France \\ ${ }^{2}$ IC2MP, Université de Poitiers, Poitiers 86073, France \\ ${ }^{3}$ Université de Haute Alsace, CNRS, IS2M UMR 7361, F-68100 Mulhouse, France \\ ${ }^{4}$ Université de Strasbourg, F-67000 Strasbourg, France
}

\begin{abstract}
$\mathrm{H}-\mathrm{ZSM}-5$ and $\mathrm{H}-{ }^{*} \mathrm{BEA}$ zeolites were hydrothermally synthesized with different Si/Al ratios $(\sim 12$ to $\sim 40)$. The physico-chemical properties of the resulting materials were fully characterized by several techniques (NMR, BET, PXRD, and pyridine thermal desorption followed by infrared spectroscopy). To assess the effect of the zeolite type and Si/Al ratio on sample reactivity, the charge separation processes between the zeolite framework and the adsorbed trans-stilbene $(t-S t)$ molecule were investigated by UV-visible diffuse reflectance and FT-Raman spectroscopy. The UV-visible absorption spectra obtained after $t$-St adsorption show a clear difference depending on the zeolite type. It appears that the radical cation resulting from $t$-St spontaneous ionization is more stabilized in the MFI-type framework than in the *BEA topology. However, the amount and stability of the electron-hole pair resulting from the radical cation evolution to a charge transfer complex are more important in the *BEA zeolite. On the basis of the experimental results and physico-chemical properties of the sample, we found that the radical cation and the electron-hole stabilities are strongly dependent on the amount of hexacoordinated aluminum $\mathrm{Al}^{(\mathrm{VI})}$ and more precisely on their environment, i.e. the distance between Brønsted sites and strong Lewis sites or Brønsted Strong Lewis Pairs (BSLPs).
\end{abstract}

Keywords: Keyword1, Keyword2, Keyword3

\section{INTRODUCTION}

Among the parameters that can influence zeolite reactivity, confinement is of high importance because the guest molecule can exhibit quite different chemical behaviours with respect to the interactions in the inner space. Thus, zeolites can be considered as solid solvents and the judicious choice of these porous materials might allow controlling chemical processes. The effects of high intrachannel electrostatic field due to aluminium, charge balancing cation and confinement of the guest molecule give rise to intermolecular non-covalent interactions that can induce many interesting reactions. [1, 2] Particularly, these remarkable intrinsic properties can include spontaneous ionization, stabilization of otherwise unstable radicals, polymerization and hole-catalyzed reactions.[3-5] Indeed, recent studies have demonstrated the determinant role of electron transfer processes in the reaction mechanisms involved in zeolite catalysis. [6-8] Nevertheless, such reactions require a specific environment to take place and depend on the appropriateness of the guestmolecule and the pore dimension. Thus, it was demonstrated that spontaneous ionization is a property of the inner surface of zeolites. [9] The bases for the spontaneous ionization process of electron donor molecules occluded in zeolites were reviewed previously [3, 10] and some of the parameters that influence the reaction have been described. The spontaneous ionization depends on the ionization

\footnotetext{
${ }^{*}$ To cite this article: T. Crémoux, I. Gener-Batonneau, A. Moissette, J.-L. Paillaud, M. Hureau, E. Ligner, C. Morais, S. Laforge, C. Marichal and H. Nouali, Influence of Framework Si/Al Ratio and Topology on Electron Transfer on Zeolites, Phys. Chem. Chem. Phys., 2019, 21(27), 14892-14903. DOI : C9CP01166H, HAL : hal-02388340

${ }^{\dagger}$ Electronic supplementary information (ESI) available: ESI
} 
potential of the guest and on the ionizing capacity of the host, which is directly related to the Si/Al ratio [11] and to the nature of the charge balancing cation. [12] The stabilization of charge separated states within the zeolite internal void space is now well-known and was often observed after sorption of polyaromatics in acidic channel type zeolites or after photolysis of polyaromatics occluded as intact molecules inside the porous void of non-acidic zeolites. The stabilization of radicals is explained by the compartmentalization of ejected electrons trapped away from the initial site of ionization. [13] Nevertheless, charge shifting reactions (hole transfer) were reported after the initial ionization and before the final charge recombination to create a long lived charge transfer complex. [1] The stabilization of radical cations highlights the electron acceptor property of zeolite but the zeolite can also act as an electron donor through $\mathrm{AlO}_{4}$ moieties. [14-16] Although some bibliographic studies suggest a correlation between the increase in aluminium content and the ionization rate of incorporated molecules and their stabilization, the interpretations proposed to explain this behaviour remain incomplete because zeolites are very often not sufficiently characterized. [1] For example, it has been proposed that increasing the aluminum content that reduces the average distance between two aluminum atoms can facilitate electron transfer and provide better stability to the system. [17] Recently, we have demonstrated that the strength of Lewis and Brønsted acidic sites and the proximity between these two types of sites are of great importance in the spontaneous ionisation process and radical cation stabilization. [18] In this paper, we examine the influence of the Si/Al ratio on intra-zeolite reactivity by characterizing the charge separated states formed after adsorption and spontaneous ionization of t-stilbene within the porous network of MFI- and *BEA-type zeolites. Our objective is to interpret the observed reaction mechanisms by linking them to the intrinsic physico-chemical properties of the host materials determined through the use of several complementary characterization techniques.

\section{EXPERIMENTAL SECTION}

\section{Silicalite-1 synthesis}

Pure silica MFI-type zeolite was synthesized following the classical method in fluoride medium. [19] The sample was calcined in air at $550{ }^{\circ} \mathrm{C}$ for 6 hours.

\section{Synthesis of H-ZSM-5 zeolites with different Si/Al ratios}

The ZSM-5 zeolites with the MFI topology were synthesized following the method described earlier. [20] Tetrapropylammonium bromide (TPABr, $\sim 98 \%$, Fluka) and sodium chloride $(\mathrm{NaCl}, \sim 99 \%$, Carlo Erba) were dissolved in distilled water and mixed with aluminum sulfate hexadecahydrate $\left(\left(\mathrm{Al}_{2}\left(\mathrm{SO}_{4}\right)_{3} \cdot 6 \mathrm{H}_{2} \mathrm{O} \sim 98 \%\right.\right.$ Fluka Pharm.). Then, after complete dissolution, a solution of sodium metasilicate pentahydrate $\left(\mathrm{Na}_{2} \mathrm{SiO}_{3} \cdot \mathrm{H}_{2} \mathrm{O}\right.$, $\sim 95 \%$, Sigma Aldrich) was added. After dissolution of the precipitate, a solution containing tetrapropylammoniumbromide, sodiumhydroxide ( $\sim 97 \%$, Carlo Erba) and sodium chloride was finally added. The $\mathrm{pH}$ was adjusted to 10 by dropwise addition of sulfuric acid ( $\sim 95 \%$, Sigma Aldrich) and the mixture was stirred vigorously for 12 hours. The resulting gels of compositions $1 \mathrm{Na}_{2} \mathrm{SiO}_{3}: \mathrm{xAl}_{2} \mathrm{SO}_{4}: 0.65 \mathrm{TPABr}: 1.9 \mathrm{NaCl}: 0.13 \mathrm{NaOH}: 42 \mathrm{H}_{2} \mathrm{O}$ with $\mathrm{x}=0.033,0.02$ and 0.011 were hydrothermally treated at $210{ }^{\circ} \mathrm{C}$ for 12 hours in a $700 \mathrm{~mL}$ MaxiTech steel autoclave equipped with a PID temperature controller. The recovered solids were washed with hot distilled water and dried overnight at $90{ }^{\circ} \mathrm{C}$. In order to release the porosity, the samples were calcined in air at $500{ }^{\circ} \mathrm{C}$ for 8 hours.

The obtained Na-ZSM-5 zeolites were exchanged three times using a $2 \mathrm{M} \mathrm{NH}_{4} \mathrm{NO}_{3}$ solution at $60{ }^{\circ} \mathrm{C}$ in order to obtain the $\mathrm{NH}_{4}$-ZSM-5 forms. The H-ZSM-5 forms were obtained by calcination in air at $550{ }^{\circ} \mathrm{C}$ for 10 hours of the ammonium exchanged zeolites.

\section{Synthesis of $\mathrm{H}-{ }^{*} \mathrm{BEA}$ zeolites with different $\mathrm{Si} / \mathrm{Al}$ ratios}

The Al-containing *BEA-type zeolites were synthesized in fluo- ride media following the method described by Jon et al. [21] Aluminum hydroxide $\left(\mathrm{Al}(\mathrm{OH})_{3}, 76.5 \%\right.$ min, Alfa Aesar) was dissolved in tetraethylammonium hydroxide (TEAOH, $40 \%$ aqueous solution, Aldrich). After complete dissolution, ammonium fluoride $\left(\mathrm{NH}_{4} \mathrm{~F}\right.$, $97 \%$, Aldrich) was added and stirred for $10 \mathrm{~min}$. Then, the water content was adjusted and the resulting cloudy solution was poured on the silica source (Zeosil-45, $\mathrm{SiO}_{2}, 100 \%$, Rhodia) and homogenized in a mortar. The 
resulting solid gels of composition $1 \mathrm{SiO}_{2}: \mathrm{yAl}(\mathrm{OH})_{3}: 0.45 \mathrm{TEAOH}: 0.4 \mathrm{NH}_{4} \mathrm{~F}: 7 \mathrm{H}_{2} \mathrm{O}$ with $\mathrm{y}=0.125,0.056$ and 0.036 were hydrothermally treated at $140{ }^{\circ} \mathrm{C}$ for 14 days in $150 \mathrm{~mL}$ Top Industrie PTFE-lined steel autoclaves. The recovered solid was washed with hot distilled water and dried overnight at $90{ }^{\circ} \mathrm{C}$. In order to release the porosity, the samples were calcined in air at $550^{\circ} \mathrm{C}$ for 10 hours.

To obtain the $\mathrm{H}-*$ BEA forms, the ammonium-containing zeolites were calcined in air at $550{ }^{\circ} \mathrm{C}$ for 10 hours.

\section{trans-Stilbene adsorption procedure}

Weighed amounts $(\sim 0.8 \mathrm{~g})$ of zeolite were introduced into an evacuable, heatable quartz cell placed in a vertical oven connected to a piping network. The sample was heated stepwise up to $450{ }^{\circ} \mathrm{C}$ under flowing dry Ar for $12 \mathrm{~h}$. Then, the sample was cooled to room temperature under dry argon. Weighed amounts of solid $t$-St corresponding to 1 molecule per unit cell (UC) were introduced into the cell under dry Ar, and then the powder mixture was shaken. After homogeneous mixing, the powder was transferred under dry argon into a quartz glass.

\section{Characterization techniques}

Global Si/Al ratios were determined by ICP-OES using a Perkin Elmer Optima 2000 DV instrument.

Powder diffractograms were collected at room temperature using a PANalytical X'Pert PRO MPD X-ray diffractometer equipped with an $\mathrm{X}^{\prime}$ Cellerator linear detector and $\mathrm{CuK}_{\alpha}$ radiation source (generator setting: 45 $\mathrm{kV}$ and $40 \mathrm{~mA}$ ). The diffraction data were collected over the angular range from 31 to $50^{\circ} 2 \theta$ with a step size of $0.017^{\circ} 2 \theta$ and a counting time of 220 s per step.

Textural properties were determined by $N_{2}$ physisorption at $77 \mathrm{~K}$, using a Micromeritics ASAP instrument. Before analysis, all samples were degassed under a secondary vacuum for $12 \mathrm{~h}$ at $350^{\circ} \mathrm{C}$. The micropore volume was evaluated from $\alpha_{s}$-plots using the Jaroniec's non porous silica adsorption isotherm, as in ref. [22]. The total pore volume was evaluated at a $P / P_{0}$ value of 0.98 , on the adsorption branch of the isotherm. Scanning electron microscopy (SEM) images were obtained using a Philips XL 30 FEG apparatus. The FT-IR quantification of both Lewis and Brønsted acid sites on the parent and modified zeolite samples was done by pyridine adsorption at $150{ }^{\circ} \mathrm{C}$ followed by FT-IR spectroscopy using a Magna Nicollet FT-IR spectrometer. The amounts of Lewis and Brønsted sites were calculated from the integrated area of the $\mathrm{PyH}^{+}$and $\mathrm{PyL}$ bands at 1545 and $1450 \mathrm{~cm}^{-1}$, respectively, corresponding to the stretching mode $v_{19 b}$ of pyridine. The experimental method was described in detail in a previous paper. [23]

${ }^{1} \mathrm{H}-{ }^{29} \mathrm{Si}$ cross-polarization magic angle spinning (CP-MAS) NMR spectra were recorded on a Bruker Avance II $300 \mathrm{WB}$ spectrometer $\left(B_{0}=7.1 \mathrm{~T}\right)$ operating at $59.59 \mathrm{MHz}$, with a ${ }^{1} \mathrm{H}$ pulse duration of $4.1 \mathrm{~ms}$ corresponding to a flip angle of $\pi / 2$, a contact time of $4 \mathrm{~ms}$ and a recycle delay of $1 \mathrm{~s}$ according to the ${ }^{1} \mathrm{H} \mathrm{T}_{1}$.

${ }^{29} \mathrm{Si}$ MAS NMR spectra were recorded with a $2.4 \mathrm{~ms}$ pulse duration corresponding to a flip angle of $\pi / 6,80 \mathrm{~s}$ of recycling delay and ${ }^{1} \mathrm{H}$ decoupling during acquisition. Samples were packed in a $7 \mathrm{~mm}$ cylindrical zirconia rotor and spun at a spinning frequency of $4 \mathrm{kHz} .{ }^{29} \mathrm{Si}$ chemical shifts were referenced to tetramethylsilane (TMS).

${ }^{27} \mathrm{Al}$ MAS NMR spectra were recorded on a Bruker Avance II 400WB spectrometer $\left(B_{0}=9.4 \mathrm{~T}\right)$ operating at 104.2 MHz using a $4 \mathrm{~mm}$ cylindrical zirconia rotor and spun at a spinning frequency of $12 \mathrm{kHz}$. Acquisition parameters are a pulse duration of $0.5 \mathrm{~ms}$ corresponding to a flip angle of $\pi / 12$ and a $0.5 \mathrm{~s}$ recycle delay. ${ }^{27} \mathrm{Al}$ chemical shifts were given relative to an aqueous solution of aluminum nitrate $\left(\mathrm{Al}\left(\mathrm{NO}_{3}\right)_{3}\right)$.

The samples were hydrated in a desiccator containing a saturated $\mathrm{NH}_{4} \mathrm{Cl}$ solution before each NMR measurement. Decompositions of the NMR spectra to extract the proportion of the corresponding species were performed using the DMfit software. [24]

Stable species and electron-hole pairs generated upon $t$-stilbene adsorption on the various samples were analyzed by UV-visible diffuse reflectance spectroscopy. The spectra were recorded in the $200-1800 \mathrm{~nm}$ range on a Cary 5000 spectrometer. The instrument was equipped with an integrating sphere using bare zeolite as the reference. The chromophore concentration was related to the intensity by using a conventional equation derived from the Kubelka-Munk phenomenological theory. In this equation: $F(R)=(1-R)^{2} / 2 R \sim K / S$, the sample is treated as a continuum, $\mathrm{R}$ is the ratio of the diffuse reflectance of the loaded zeolite to that of the neat zeolite, $\mathrm{K}$ is 
the absorption coefficient proportional to the concentration of the chromophore and $\mathrm{S}$ is the scattering coefficient of the powder.

\section{Physico-chemical characterization of the zeolites}

Elemental analysis of samples in protonic forms is used to determine the overall $\mathrm{Si} / \mathrm{Al}$ ratio and to ensure the effectiveness of the exchange required to obtain the acid form. The overall $\mathrm{Si} / \mathrm{Al}$ ratios are presented in Table 1 along with the sample nomenclature. Sodium concentrations after ammonium exchange are below the detection threshold of the technique.

Table 1. Physico-chemical characterizations of H-ZSM-5 and H-*BEA zeolites and difference between the global and framework elemental compositions.

\begin{tabular}{|c|c|c|c|c|c|c|c|}
\hline Samples & $\mathrm{Si} / \mathrm{Al}_{\text {global }}{ }^{a}$ & $\begin{array}{l}\mathrm{V}_{\text {micro }}{ }^{b} \\
\left(\mathrm{~cm}^{3} \mathrm{~g}^{-1}\right)\end{array}$ & $\begin{array}{l}V_{\text {total }} \\
\left(\mathrm{cm}^{3} \mathrm{~g}^{-1}\right)\end{array}$ & $\begin{array}{l}\text { Brønsted sites } \\
\left(\mu \mathrm{mol} \mathrm{g}{ }^{-1}\right)\end{array}$ & $\begin{array}{l}\text { Lewis sites } \\
\left(\mathrm{mmol} \mathrm{g}^{-1}\right)\end{array}$ & $\begin{array}{l}\% A l^{(V I)} \\
\left.{ }^{27} \mathrm{Al} \mathrm{NMR}\right)\end{array}$ & $S i / A l_{f}^{c}$ \\
\hline MFI_SA12 & 12 & 0.17 & 0.25 & 947 & 222 & 9.5 & 13.5 \\
\hline MFI_SA19 & 19 & 0.17 & 0.22 & 796 & 65 & 6.3 & 20 \\
\hline MFI_SA35 & 34.5 & 0.17 & 0.20 & 446 & 33 & 0.7 & 34.5 \\
\hline Silicalite-1 & $\infty$ & 0.17 & 0.19 & 0 & 0 & - & - \\
\hline *BEA_SA12 & 12 & 0.20 & 0.33 & 371 & 260 & 25 & 16 \\
\hline *BEA_SA24 & 24 & 0.17 & 0.39 & 392 & 102 & 18 & 29 \\
\hline *BEA_SA38 & 38 & 0.20 & 0.32 & 251 & 55 & 15 & 45 \\
\hline
\end{tabular}

Zeolite particles have been observed by scanning electron microscopy. H-ZSM-5 samples containing aluminum (MFI_SA12, MFI_SA19 and MFI_SA35) exhibit agglomerated particles. The agglomerate sizes are homogeneous for all the samples and around 4-6 $\mu \mathrm{m} \mathrm{m}$ in size. Silicalite-1 crystals are not agglomerated and form large platelets $\left(4 \times 8 \mu \mathrm{m}^{2}\right)$ free of impurities. $*$ BEA zeolite crystallites are less agglomerated and look smaller with a square pillow form. The crystallite size increases with the Si/Al ratio but remains in the micrometre range (Fig. S1, ESI $\dagger$ ).

$\mathrm{X}$-ray diffraction was used to characterize the zeolite samples and to verify the absence of unwanted or amorphous phases. The diffractograms obtained are shown in Fig. S2, ESI. $\dagger$ The diffractograms are characteristic of the expected phases (H-ZSM-5 or silicalite-1 or H-*BEA zeolites) and no other additional phase is observed. In the case of $\mathrm{H}^{*} \mathrm{BEA}$ zeolites, the presence of at least two polymorphs is clearly evidenced as usual for this zeolite type. The positions of the diffraction peaks shift slightly towards small angles when Si/Al decreases. This shift towards small angles is the consequence of the crystalline unit cell contraction caused by the decrease in aluminium content.

Nitrogen physisorption isotherms at $77 \mathrm{~K}$ are shown in Fig. S3, ESI. $\dagger$ These isotherms are of type I, characteristic of microporous materials. In the case of ZSM-5 samples of different $\mathrm{Si} / \mathrm{Al}$ ratios, a hysteresis loop is observed at desorption. This H4 type loop is characteristic of zeolite materials whose crystallites hardly agglomerate. [25] This hysteresis and the increase in the adsorbed volume at high relative pressure values appear to increase when the $\mathrm{Si} / \mathrm{Al}$ ratio decreases. The change observed in the hysteresis loop results from either the presence of intracrystalline mesopores or intercrystalline mesopores due to a high rate of agglomeration of the crystallites. In addition, Fig. S3, ESI $\dagger$ also shows that the adsorption isotherm of the silicalite-1 sample has a step and a hysteresis loop in the low relative pressure range $\left(P / P_{0}=0.2\right)$, which is explained by a characteristic phase change of this material. [25] For the *BEA zeolite samples, the plateau is less pronounced than in the case of the ZSM-5 samples, indicating a higher external surface area due to the presence of internal mesopores with a very large distribution. These mesopores were certainly formed during the calcination step. Table 1 lists 
the parameters calculated by the analysis of the nitrogen physisorption isotherms. Except for *BEA_SA24, the microporous volume does not vary with $\mathrm{Si} / \mathrm{Al}$ and constitutes most of the porosity of the sample. The mesopore proportion is the same for the *BEA samples and higher than that observed for the ZSM-5 ones. *BEA zeolite is less robust than MFI and framework dealumination may occur during the calcination step leading to mesopore formation.

Since the chemical shift of ${ }^{29} \mathrm{Si}$ depends on its coordination with $\mathrm{O}-\mathrm{Si}, \mathrm{O}-\mathrm{H}$ and $\mathrm{O}-\mathrm{Al}$ groups, observation of the NMR spectra makes it possible to study the silicon environment. The ${ }^{29} \mathrm{Si}$ MAS NMR spectra of silicon with and without polarization transfer from ${ }^{1} \mathrm{H}$ are shown respectively in Fig. 1 for MFI-type and *BEA zeolites. The ${ }^{29}$ Si MAS-NMR spectra of the MFI-type zeolites (Fig. 1A) exhibit at least three resonances at $-115,-112$ and $-106 \mathrm{ppm}$. The resonances at -115 and $-112 \mathrm{ppm}$ correspond according to the literature [26, 27] to $\mathrm{Q}_{4}(0 \mathrm{Al})$, i.e. $\mathrm{Si}(\mathrm{OSi})_{4}$, species. The resonance centered at $-106 \mathrm{ppm}$ can be attributed not only to $\mathrm{Q}_{4}(1 \mathrm{Al})$, i.e. $\mathrm{Si}(\mathrm{OSi})_{3}(\mathrm{OAl})$, species but also to $\mathrm{Q}_{3}$, i.e. $\mathrm{Si}(\mathrm{OSi})_{3}(\mathrm{OH})$, species for which the chemical shift domain overlaps with that of the $\mathrm{Q}_{4}(1 \mathrm{Al})$ species. [26, 27] This resonance decreases significantly from 24 to $11 \%$ of the total signal when the global $\mathrm{Si} / \mathrm{Al}$ ratio increases from 12 to 35. This observation is in agreement with the lower quantity of aluminum atoms in the zeolite framework at higher $\mathrm{Si} / \mathrm{Al}$ ratios.
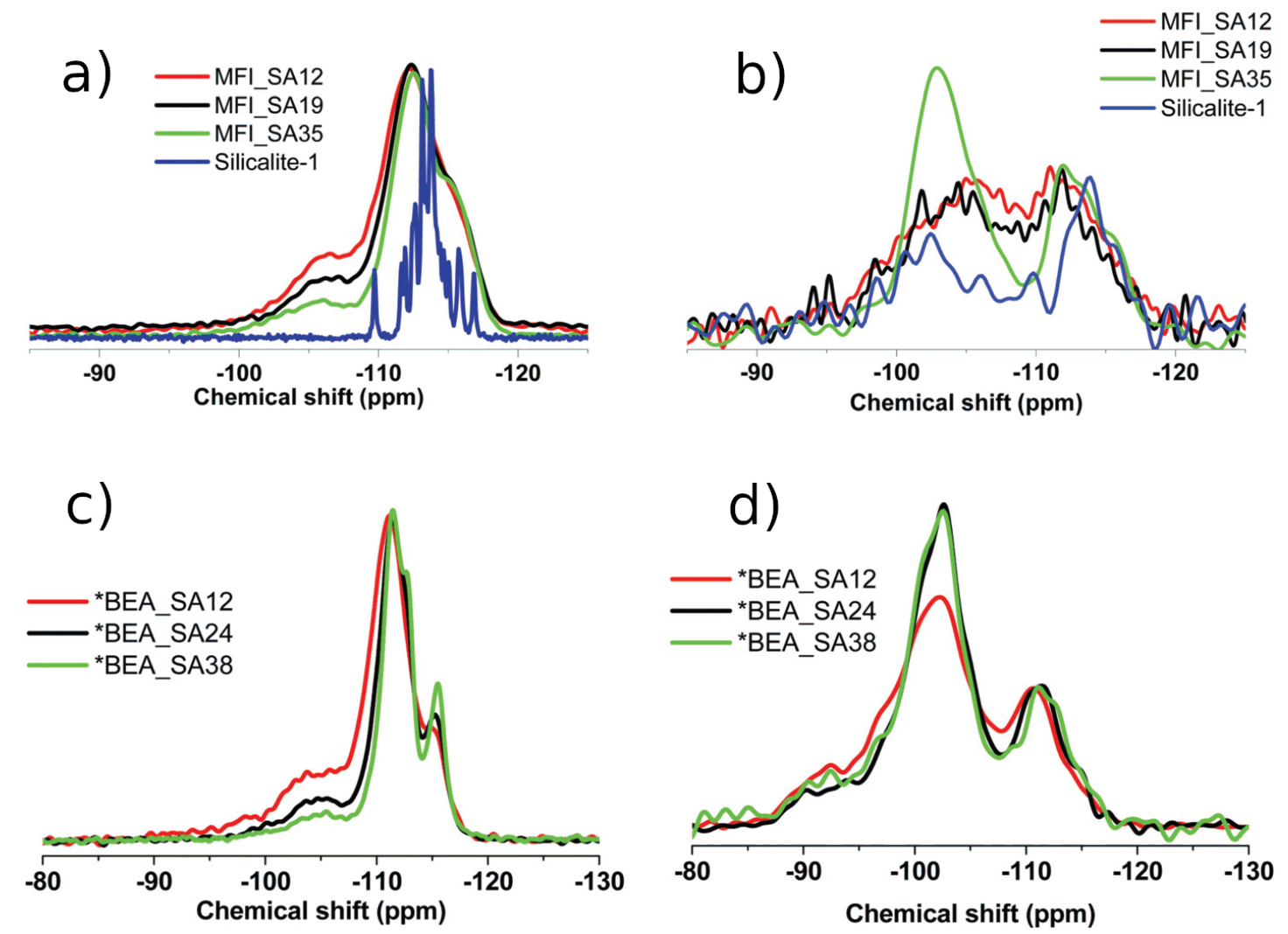

Fig. 1. ${ }^{29} \mathrm{Si}$ MAS (a) and ${ }^{1} \mathrm{H}-{ }^{29} \mathrm{Si}$ CPMAS NMR spectra (b) of H-ZSM-5 and silicalite-1 zeolites. ${ }^{29}$ Si MAS (c) and ${ }^{1} \mathrm{H}-{ }^{29} \mathrm{Si}$ CPMAS NMR spectra (d) of $\mathrm{H}-*$ BEA zeolites.

In addition, in some cases, the use of silicon NMR can reveal small variations in the local environment of this element. Indeed, for the silicalite-1 sample, the non-equivalent crystallographic sites occupied by silicon lead to resonances that are resolved in the spectrum. [26, 28]

${ }^{1} \mathrm{H}-{ }^{29} \mathrm{Si}$ NMR CPMAS spectra of the MFI-type zeolites are shown in Fig. 1B. This experiment shows the presence of silanols. Two large resonances are detected, centred at about $-103 \mathrm{ppm}$, which is characteristic of silanols, and at -113 ppm indicating spatial proximity between silanols and $\mathrm{Q}_{4}$ species. Except for MFI_SA35, the signal-to-noise ratio of the spectra is very low, indicating a small amount of silanols. 
The ${ }^{29} \mathrm{Si}$ MAS NMR spectrum of *BEA_SA38 zeolite shown in Fig. 1C exhibits four resonances corresponding to $\mathrm{Q}_{4}(-115,-112.5$ and $-111 \mathrm{ppm})$ and $\mathrm{Q}_{3}(-105 \mathrm{ppm})$ species. According to the literature, [29] the resonances at -115 and $-111 \mathrm{ppm}$ are either attributed to $\mathrm{Si}$ atoms located at non-equivalent crystallographic sites or may result from the two different stacking orders corresponding to polymorphs A and B of beta zeolite. [30] The comparison of the MAS and CPMAS NMR experiments (Fig. 1C and D) indicates that the resonance centred at $-105 \mathrm{ppm}$ is the superposition of the $\mathrm{Si}(\mathrm{OSi})_{3} \mathrm{OH}$ species detected at $-103 \mathrm{ppm}$ in the CPMAS NMR spectrum and $\mathrm{Si}(\mathrm{OSi})_{3} \mathrm{OAl}$ species expected in the same chemical shift range. Upon increasing the aluminum content, all the resonances are broadened, in agreement with a higher distribution of environments. As expected, the area of the resonance assigned to the $\mathrm{Si}(\mathrm{OSi})_{3} \mathrm{OAl}$ species increases with the aluminum content. Furthermore, a weak signal at $-98 \mathrm{ppm}$ is detected for the *BEA_SA24 and SA12 samples also indicating small amounts of $\mathrm{Si}(\mathrm{OSi})_{2}(\mathrm{OAl})_{2}$ species. The corresponding CPMAS NMR spectra suggest the presence of some $\mathrm{Si}(\mathrm{OSi})_{2} \mathrm{OH}_{2}$ species detected at $-92 \mathrm{ppm}$ while the resonance at $-102 \mathrm{ppm}$ corresponding to silanols decreases significantly upon aluminum incorporation.

${ }^{27} \mathrm{Al}$ MAS NMR spectra provide information about the Al local environment and in particular its coordination. Indeed, chemical shifts of the tetrahedral framework of aluminum atoms are clearly different from those of aluminum atoms in octahedral coordination usually associated with extraframework (EFAL) species. [31] ${ }^{27} \mathrm{Al}$ MAS NMR spectra of the ZSM-5 and *BEA samples are shown in Fig. 2.
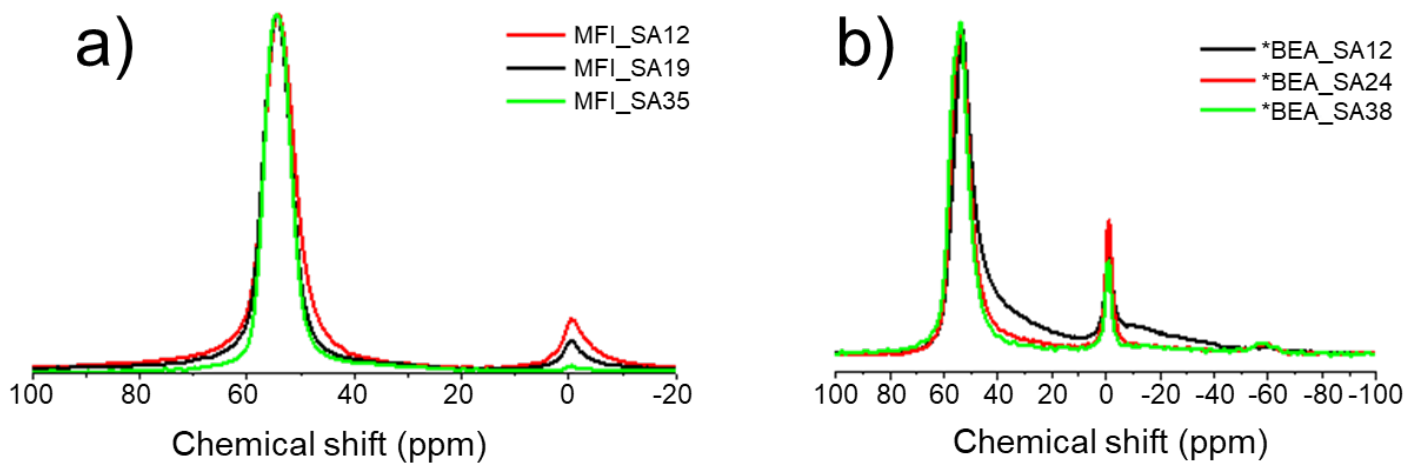

Fig. 2. ${ }^{27} \mathrm{Al}$ MAS NMR spectra of (a) H-ZSM-5 and (b) *BEA-type zeolites. Only the isotropic region is shown. (*): spinning sideband.

Two resonances are clearly seen in the spectra of the MFI-type zeolites (Fig. 2A). The most intense centered at $54 \mathrm{ppm}$ corresponds to the tetrahedral aluminum signal. A less intense resonance appears at $0 \mathrm{ppm}$ and is assigned to octahedral EFAL aluminium. [27, 32] In the *BEA zeolite spectra, these two resonances are also clearly observed for the *BEA_SA38 and *BEA_SA24 samples (Fig. 2B). The sharp resonance at 0 ppm suggests ordered octahedral species. A shoulder at $57 \mathrm{ppm}$ attributed to $\mathrm{Al}$ framework species occupying different crystallographic sites is worth noting for these two samples. [33] With the increase of the Al content, this shoulder is no longer visible and concomitantly the appearance of two additional broad components is observed. One centered at around $-10 \mathrm{ppm}$ thus corresponds to octahedral aluminum species either distorted [30] or with a distribution of environments. The other one, detected between 37 and $45 \mathrm{ppm}$, probably reflects tetrahedral aluminum species with a very distorted environment. [30]

Since the ${ }^{27} \mathrm{Al}$ MAS NMR spectra were recorded under quantitative conditions, the decomposition of the signals makes it possible to obtain the $\mathrm{Al}^{(\mathrm{VI})}$ proportion (Table 1).

Decreasing the $\mathrm{Si} / \mathrm{Al}$ ratio increases the proportion of extraframework aluminium for the two types of zeolite frameworks. Nevertheless, *BEA samples have $\mathrm{Al}^{(\mathrm{VI})}$ proportions higher than ZSM-5 zeolites. This is certainly due to the higher framework disorder and to the intergrowth of several polymorphs. For ZSM-5 zeolite, EFAL species are observed for $\mathrm{Si} / \mathrm{Al}$ ratios lower than 20. 
The $\mathrm{Si} / \mathrm{Al}_{\mathrm{f}}$ ratio shown in Table 1 can also be determined from the decomposition of the ${ }^{27} \mathrm{Al}$ MAS NMR spectra. It accounts only for the $\mathrm{Si}$ and $\mathrm{Al}$ atoms constituting the framework. The results are in reasonable agreement with those obtained by ICP-OES. Nevertheless, the $\mathrm{Si} / \mathrm{Al}_{\mathrm{f}}$ ratios are higher than those deduced from chemical analysis because, in the latter case, all aluminium atoms (both lattice and extraframework) are taken into account.

H-form zeolites have hydroxyl groups that can be evidenced by infrared spectroscopy. Fig. 3 shows the hydroxyl region of MFI- and *BEA-types zeolites after pretreatment. All the presented infrared absorption spectra were normalized to $10 \mathrm{mg}$ of dehydrated zeolite. In the spectra, four bands are clearly visible and their attribution is well documented in the literature. [34] The bands centred at $3665 \mathrm{~cm}^{-1}$ and $3780 \mathrm{~cm}^{-1}$ correspond to the vibrations of hydroxyl stretching linked to aluminum atoms that generates Lewis acidity. The band at $3665 \mathrm{~cm}^{-1}$ is usually assigned to the EFAL species. [35] The band at $3780 \mathrm{~cm}^{-1}$ was attributed by some authors to the EFAL species [36] or to tricoordinated aluminol groups partially linked to the zeolite framework. [37, 38] The increase in the intensity of these bands is consistent with the increase in the EFAL proportion determined by the ${ }^{27} \mathrm{Al}$ NMR experiment when the $\mathrm{Si} / \mathrm{Al}$ ratio decreases. The absorption band at around $3740 \mathrm{~cm}^{-1}$ corresponds to zeolite silanols. This band results from two contributions. The higher contribution at around $3745 \mathrm{~cm}^{-1}$ is generally ascribed to isolated silanol located on the external zeolite surface. The contribution at $3735 \mathrm{~cm}^{-1}$ is related to internal silanols associated with structural defects. [39] For the *BEA samples, the silanol band is very prominent, indicating the presence of a significant amount of silanol not only on the external surface of the crystallite but also as internal structural defects due to the intergrowth of two different polymorphs. Furthermore, structural defects are also clearly seen for ZSM-5 samples with ratios of 19 and 35 . This is consistent with the ${ }^{29} \mathrm{Si}$ CPMAS NMR spectrum of MFI_SA35 zeolite that exhibits an increased number of silanol species in comparison with the two other MFI-type samples. The band centred at $3610 \mathrm{~cm}^{-1}$ corresponds to the stretching vibrations of the bridging hydroxyl groups responsible for the Brønsted acidity. The increase in the intensity of this band is consistent with the $\mathrm{Si} / \mathrm{Al}$ ratio decrease for the ZSM-5 sample but surprisingly not for *BEA ones.
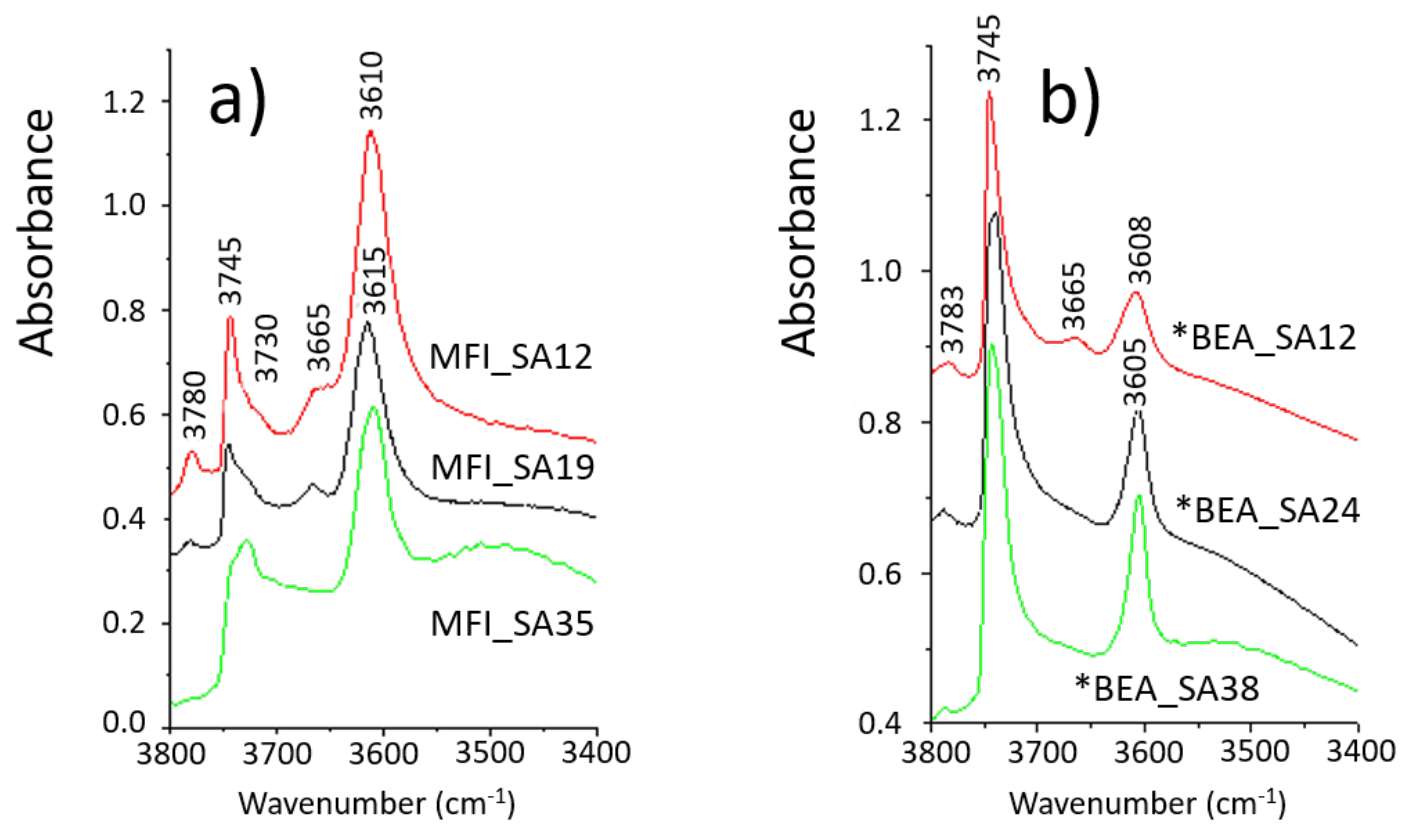

Fig. 3. FTIR spectra in the range of hydroxyl vibrations for (a) H-ZSM-5 and (b) H-*BEA-type zeolites.

The adsorption and thermo-desorption of pyridine at different temperatures allow probing the hydroxyl group acidities. For example, Fig. S4A and C, ESI $\dagger$ show the FTIR spectra recorded after pyridine desorption at different temperatures for the MFI_SA12 and *BEA_SA12 samples. After desorption at $150{ }^{\circ} \mathrm{C}$, the bridging 
hydroxyl band $\left(3610 \mathrm{~cm}^{-1}\right)$ and the band at $3780 \mathrm{~cm}^{-1}$ disappear completely, indicating that these hydroxyl groups are sufficiently acidic to retain pyridine at $150{ }^{\circ} \mathrm{C}$ and are totally accessible. The intensity of the band associated with the EFAL species $\left(3665 \mathrm{~cm}^{-1}\right)$ decreases but it does not disappear completely. At this point, it is difficult to say if it is the consequence of their acid strength or their accessibility. The silanol contributions remain largely undisturbed by pyridine whereas all of them are accessible to the pyridine molecule. As is well known, in zeolites, silanols are not sufficiently acidic to retain pyridine at $150{ }^{\circ} \mathrm{C}$. At the same time, bands attributed to the interaction of pyridine with different acidic sites appear in the $1700-1430 \mathrm{~cm}^{-1}$ region (Fig. S4B and D, ESI $\dagger$ ). These bands decrease in intensity as the desorption temperature of pyridine increases, allowing restoration of the intensity of bands from the hydroxyl region. However, at $450{ }^{\circ} \mathrm{C}$, some acidic sites still remain in interaction with pyridine because the 3780 and $3610 \mathrm{~cm}^{-1}$ bands are never fully reconstructed.

The Brønsted and Lewis acidity quantification was carried out by integrating the bands corresponding to pyridine interacting with a Brønsted site (pyridinium ion) centered at $1545 \mathrm{~cm}^{-1}$ and the band centered at 1455 $\mathrm{cm}^{-1}$, which is characteristic of the pyridine interaction with a Lewis site. The results are tabulated in Table 1 for the pyridine desorption temperature of $150{ }^{\circ} \mathrm{C}$, which allows the determination of the total acidities. As expected and in agreement with the NMR results, Lewis acid sites increase when the Si/Al ratio decreases. The number of Lewis acid sites is lower in ZSM-5 than in *BEA zeolites for which these sites are partly formed in the calcination step. According to the $\mathrm{Si} / \mathrm{Al}$ framework ratio, the Brønsted acid sites remaining in interaction with pyridine are lower in number than expected.

With respect to characterization of the number of strong Lewis acid sites, examination of the pyridine band interacting with Lewis acid sites at $1455 \mathrm{~cm}^{-1}$ is more complex. For a desorption temperature of $250{ }^{\circ} \mathrm{C}$, a shoulder at about $1462 \mathrm{~cm}^{-1}$ appears on this band. The intensity of this new contribution that depends on the sample under consideration increases between 250 and $450{ }^{\circ} \mathrm{C}$. In the literature, [23, 40] this contribution is attributed to the formation of an iminium ion as a result of the proximity of an acidic Brønsted site and a strong Lewis site (Fig. 4), forming a Brønsted-strong Lewis pair (BSLP). So, the iminium band is proportional to the BSLP amount.

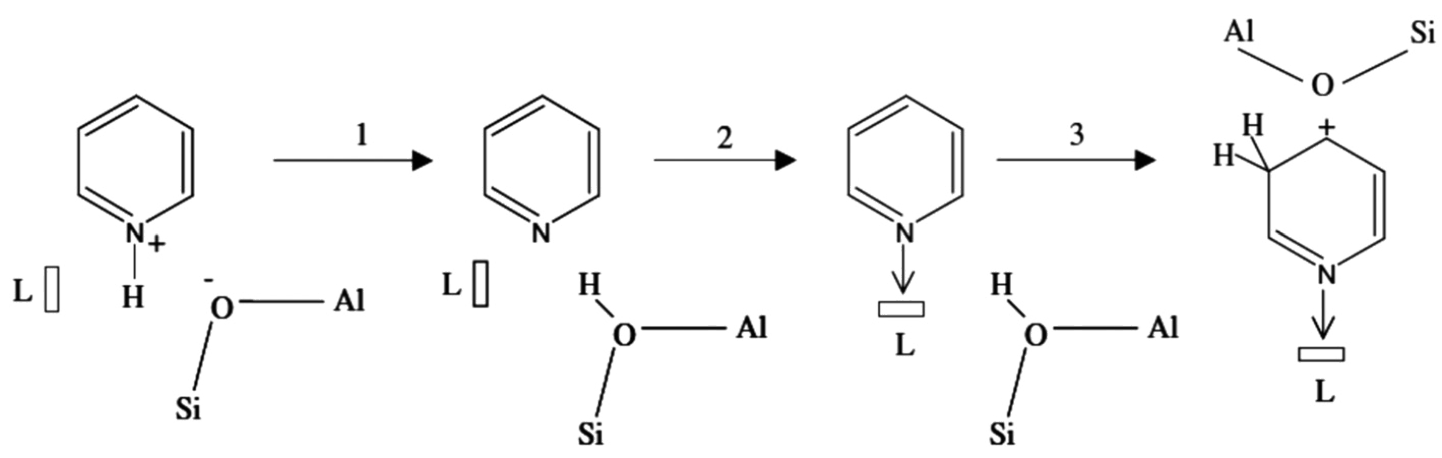

Fig. 4. Iminium formation mechanism from the Brønsted-strong Lewis pair (from ref. [40]).

In a previous paper, [18] we established that the formation of this pair is linked to the ratio between BSLP and strong Lewis sites that are involved in the charge transfer process.

This feature is shown in Fig. 5a and b, which respectively represents the evolution of the area of the iminium band as a function of Brønsted acid site concentration (Fig. 5a) and $\mathrm{Al}^{(\mathrm{VI})}$ proportion determined by ${ }^{27} \mathrm{Al}$ MAS NMR (Fig. 5b). The two graphs show that iminium amount increases with the Brønsted acid site concentration and the $\mathrm{Al}^{(\mathrm{VI})}$ percentage for the two zeolite types. Nevertheless, for high concentrations of Brønsted sites (MFI_SA12 and MFI_SA19), the iminium intensity no longer increases. High $\mathrm{Al}^{(\mathrm{VI})}$ ) percentages that are mostly related to Lewis acidity also contribute to the increase of iminium amount. However, two different behaviors are shown in Fig. 5b depending on the zeolite type. With the exception of the BEA_SA12 sample for which the iminium intensity is close to that of MFI_SA12, BSLP formation in *BEA zeolites requires a higher $\mathrm{Al}^{(\mathrm{VI})}$ proportion than for MFI since iminium intensities appear to be lower than in MFI. 
The ratio between BSLP and strong Lewis sites labelled BSLP proportion was also calculated to highlight the results. The BSLP proportion was obtained by calculating the ratio of the band area at $1462 \mathrm{~cm}^{-1}$ to the area of the total absorption band in the $1475-1430 \mathrm{~cm}^{-1}$ region of the FTIR spectrum recorded during pyridine desorption at $450{ }^{\circ} \mathrm{C}$.
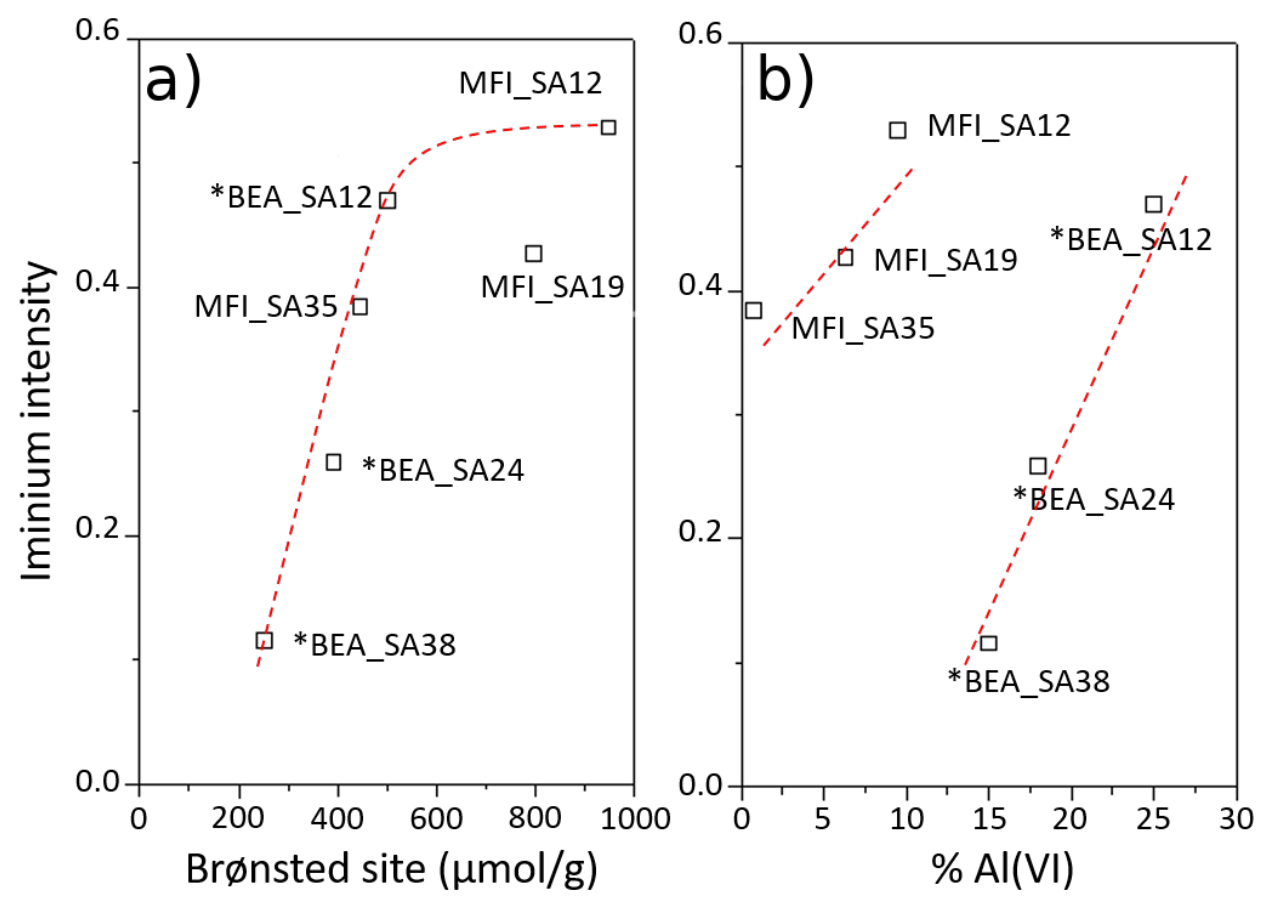

Fig. 5. Iminium intensity versus (a) Brønsted site concentration and (b) $\mathrm{Al}^{(\mathrm{VI})}$ percentage.

This ratio has been plotted in Fig. 6 versus $\mathrm{Al}^{(\mathrm{VI})}$ content, which is representative of the whole Lewis sites. As shown in Fig. 6, the proportion of strong Lewis sites involved in a BSLP is higher in MFI zeolite than in *BEA. This proportion decreases when the number of $\mathrm{Al}(\mathrm{VI})$ increases, which can be explained by a decrease of the Lewis and Brønsted acid strength [34] when the framework Si/Al ratio decreases.

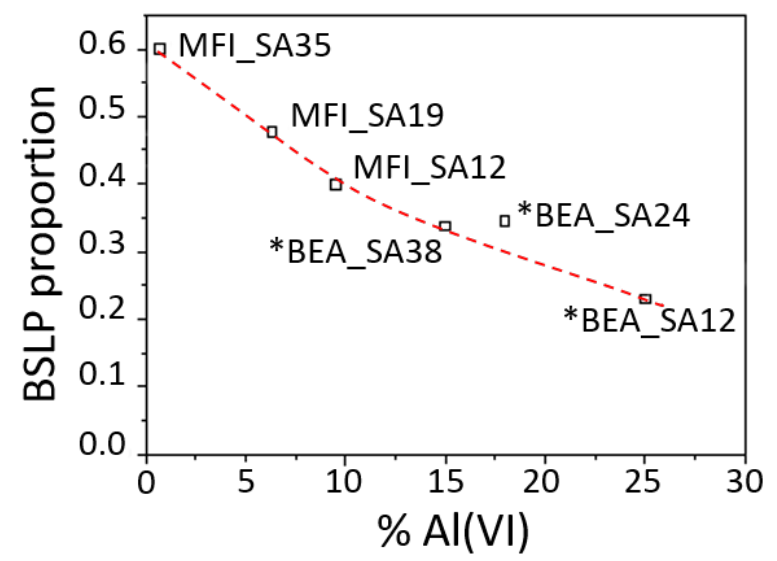

Fig. 6. BSLP proportion as a function of EFAL content.

\section{Charge transfer in zeolites of different $\mathrm{Si} / \mathrm{Al}$ ratios}

In order to assess the impact of the $\mathrm{Si} / \mathrm{Al}$ ratio and to understand the nature of the acidic sites involved in the reactivity, experiments were carried out by adsorbing $t$-stilbene on the two zeolites of different topologies (MFI 
and $* \mathrm{BEA}$ ) with various $\mathrm{Si} / \mathrm{Al}$ ratios. After mixing, the adsorption, ionization and electron transfer processes were monitored as a function of time for several months by diffuse reflectance UV-visible absorption and FT-Raman spectroscopies.

Immediately after mixing, the ZSM-5 samples show a similar evolution with the observation of the characteristic band of the radical cation $t-\mathrm{St}^{+} \bullet$ at $475 \mathrm{~nm}$ showing spontaneous ionization of $t$-stilbene. Gradually, the contributions of a new species, the charge transfer complex (CTC), observed at 560 and $620 \mathrm{~nm}$ in the visible spectral range, appear and develop. The spectral features of this long lived charge separated state and its formation mechanism related to the electron donor property of zeolite were detailed in previous papers. [16] The spectra recorded for ten hours, fourteen days and nine months after mixing $t$-stilbene with H-ZSM-5 zeolites of different $\mathrm{Si} / \mathrm{Al}$ ratios are shown in Fig. 7.
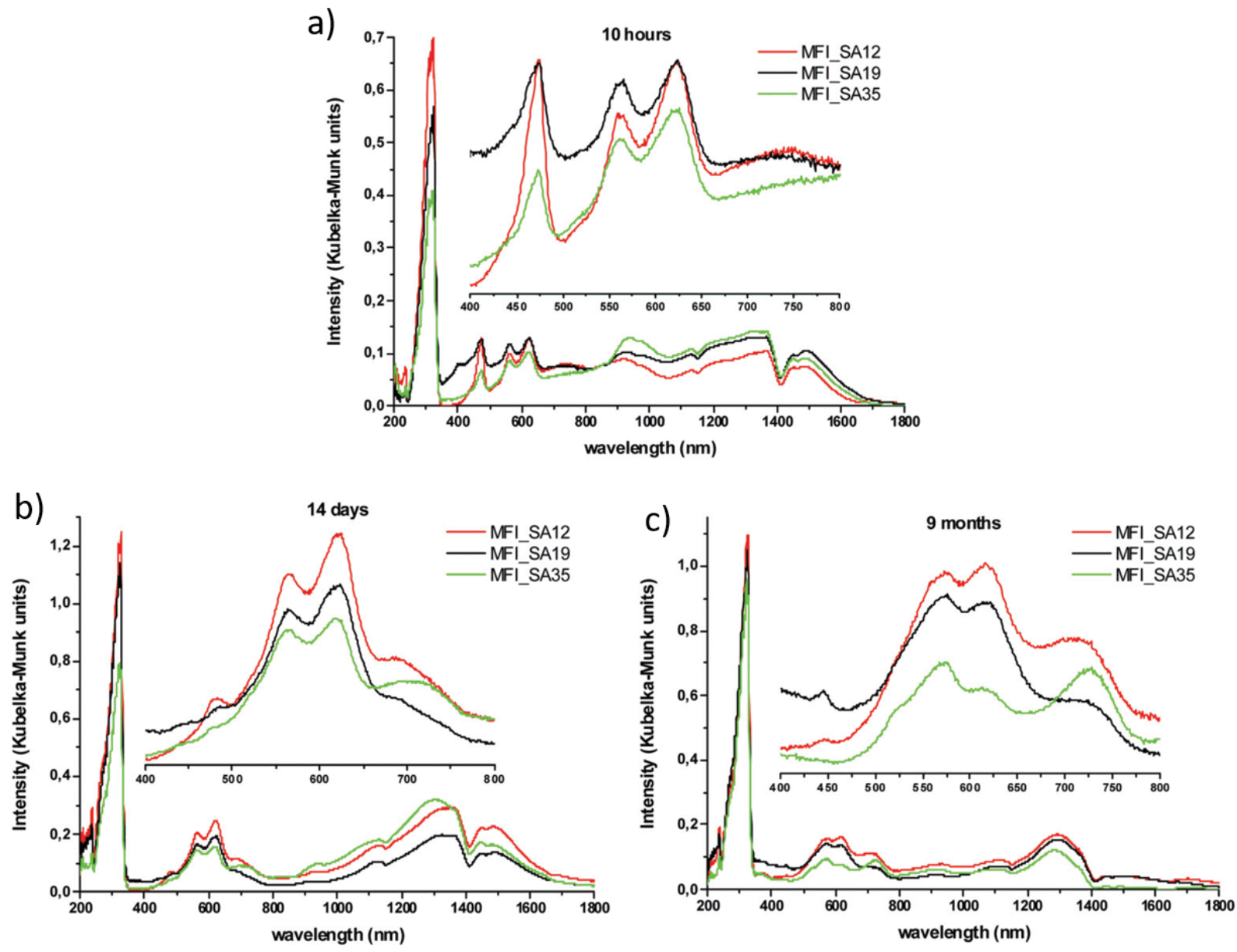

Fig. 7. Diffuse reflectance UV-vis spectra recorded (a) 10 hours, (b) 14 days and (c) 9 months after mixing $t$-St and $\mathrm{H}-\mathrm{ZSM}-5$ of Si/Al ratios of 12,19 and 35 .

The evolutions of the spectral contributions for radical cation $t-\mathrm{St}^{+\bullet}$ and the CTC obtained after mixing $t$-St with each of the MFI-type zeolites have been plotted as a function of time and are shown in Fig. 8A and B. It appears that the maximum intensity of the radical cation is reached very rapidly (less than 3 hours for the three samples) and thereafter, the intensity of $t-\mathrm{St}^{+} \bullet$ only decreases. Fig. 8 also shows that the maximum ionization yield increases with the aluminum content. Moreover, it has been shown that the density of Brønsted acid sites, considered to be one of the essential parameters for the activity of solid acidic catalysts, is closely correlated to the Al concentration of the H-ZSM-5 zeolite framework. [41]

The *BEA sample behaviour after t-stilbene adsorption is completely different in comparison with the 

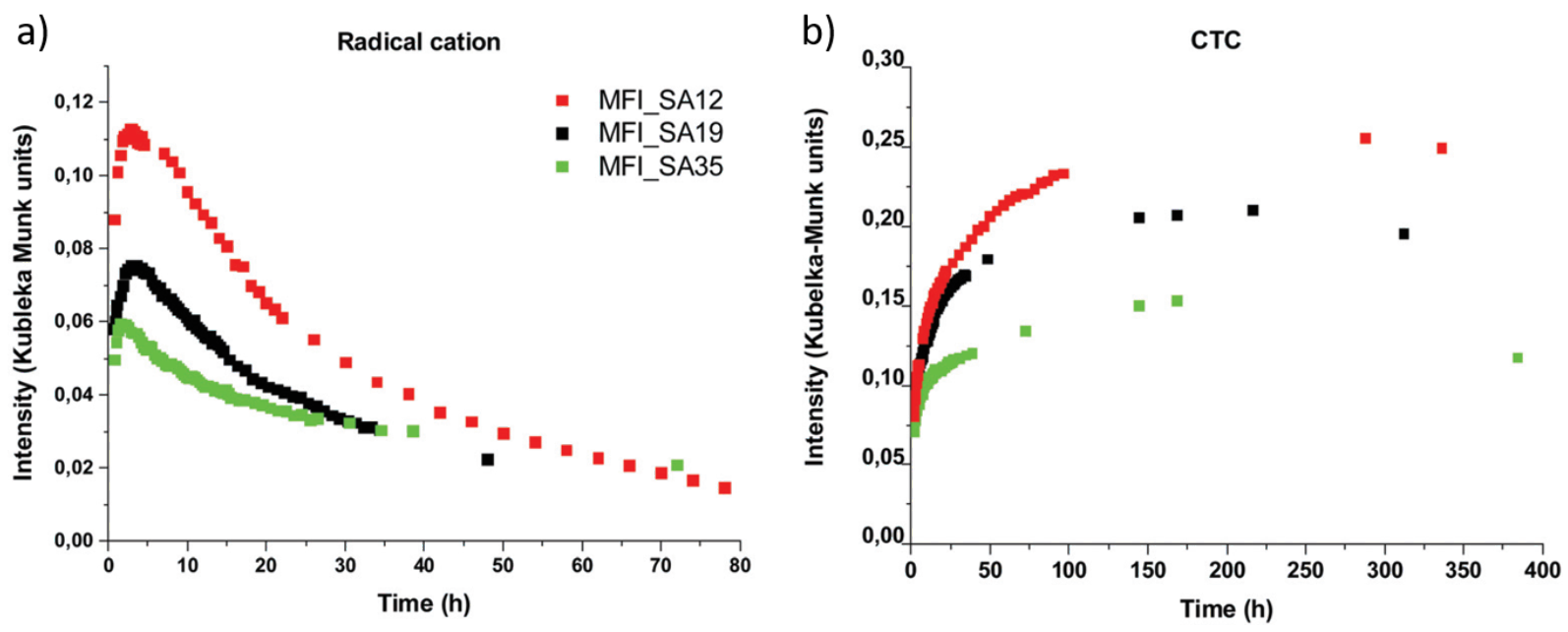

Fig. 8. Evolutions of (a) radical cation and (b) CTC contributions as a function of time after mixing t-stilbene and acidic H-ZSM-5 zeolites with $\mathrm{Si} / \mathrm{Al}$ ratios of 12, 19 and 35.

MFI-type zeolites. The spectra recorded for 15, 18 and 21 days after mixing $t$-stilbene with the different $* \mathrm{BEA}$ zeolites are shown in Fig. S5, ESI. $\dagger$ The radical cation signal is very weak and can hardly be detected for the first thirty minutes after mixing $t$-stilbene with *BEA_SA12 and *BEA_SA24 while a small but clear signal appears for *BEA_SA38. However, the CTC contribution is clearly visible at 496 and $615 \mathrm{~nm}$ for *BEA_SA12 and 24. As the CTC formation mechanism requires radical cation formation, [18] as the first step, the disappearance of the radical cation spectral signature is linked to its poor stabilization in the *BEA framework at a low Si/Al ratio. In addition, to obtain structural information about the nature of the adsorbed system in the channels, the samples were also characterized by Raman scattering spectroscopy. Two months after $t$-stilbene adsorption, the FT-Raman spectra of the samples are all similar (Fig. S6, ESI $\dagger$ ). No band corresponding to the neutral $t$-stilbene molecule is observed at $1639 \mathrm{~cm}^{-1}$, indicating the total conversion of $t$-stilbene (within the detection limit of the technique). The bands observed at 1600, 1585, 1336, 1190, and finally $997 \mathrm{~cm}^{-1}$ were described in previous studies and are attributed to the charge transfer complex. [16] The relative intensities of the lines are similar for all the samples and no line associated with the radical cation is detected. The system is thus globally stabilized in the form of a CTC and the observed lines correspond to the vibration modes of the $t$-stilbene molecule whose environment is disturbed by the presence of unpaired electrons.

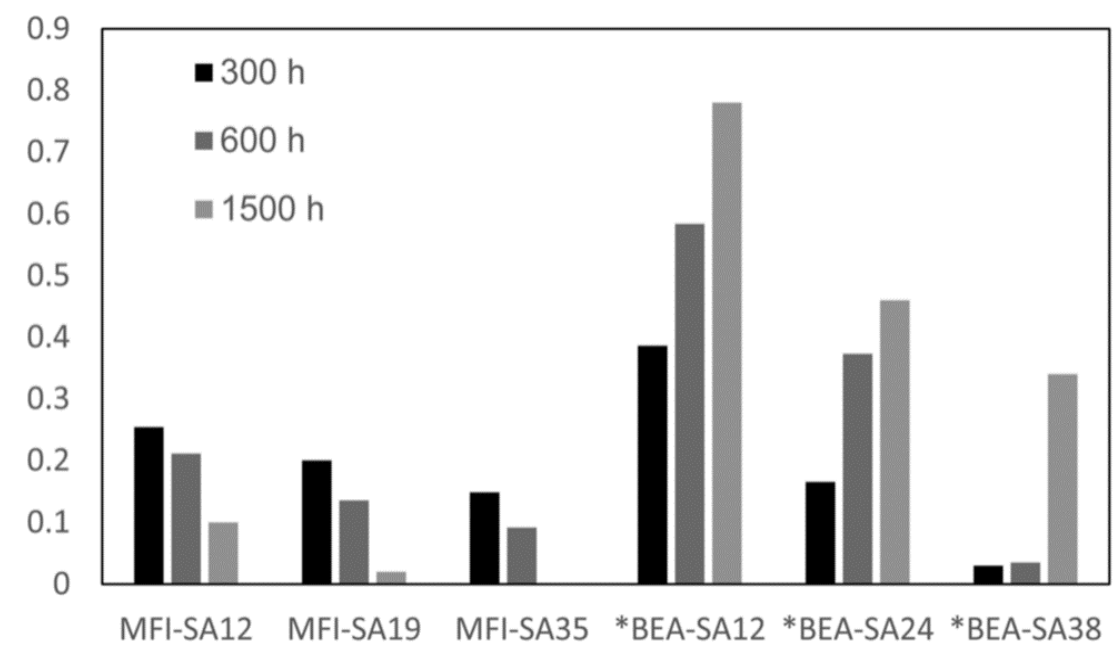

Fig. 9. CTC amounts formed in H-*BEA and H-ZSM5 zeolites after $300 \mathrm{~h}, 600 \mathrm{~h}$ and $1500 \mathrm{~h} t$-St contact time. 


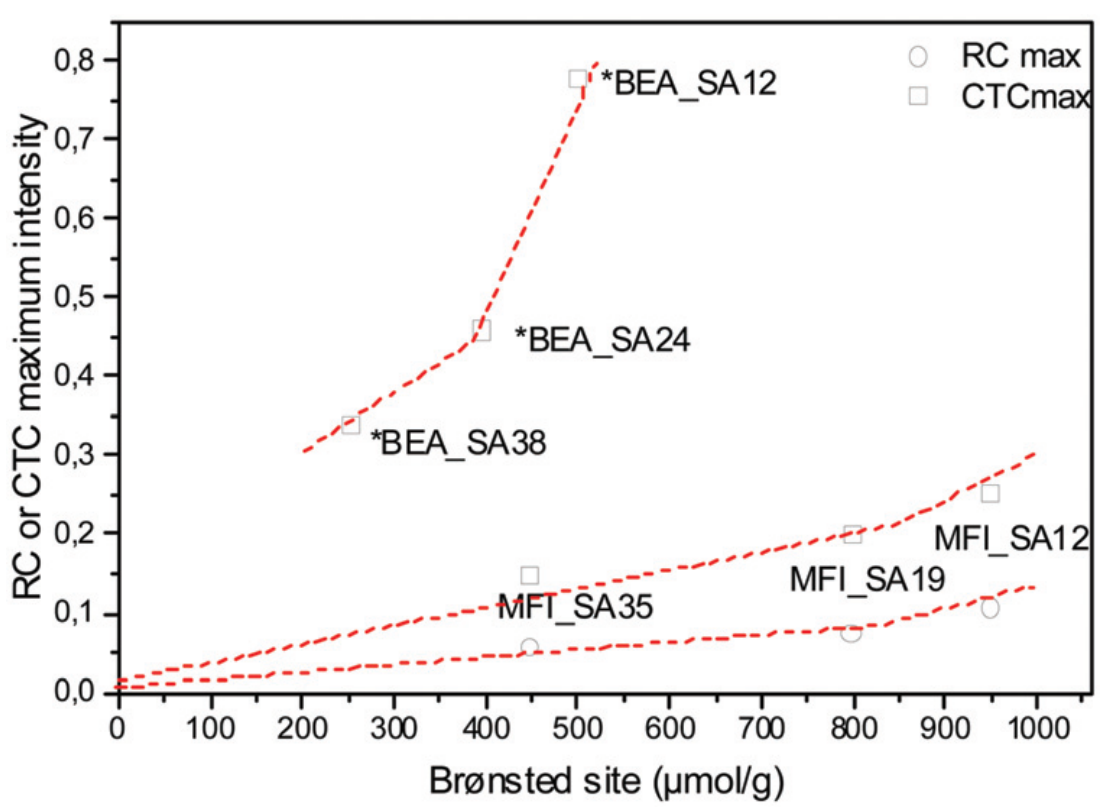

Fig. 10. $t$-St radical cation maximum intensity in ( $\bigcirc)$ H-ZSM-5 zeolites and ( $\square$ ) CTC maximum intensities in H-*BEA and H-ZSM-5 zeolites versus Brønsted site concentration.

Even if the disappearance of the radical cation can take place directly by geminated recombination, the evolution of the relative concentrations of the radical cation and CTC demonstrates an electron transfer process that reflects the oxidizing power of the radical cation $\left(E_{o x}=1.75 \mathrm{~V} / \mathrm{SCE}\right)$ with respect to the electron donor character of the zeolite framework. [42] As described in many studies carried out with this type of polyaromatic molecule, [1] the radical cation captures another electron belonging to the internal surface of the zeolite by transfer of electronic hole to generate a long-lived electron/hole pair that spectrally leads to a charge transfer complex band. Fig. 8B shows that the CTC reaches its maximum intensity after about 300 hours for H-ZSM-5 samples and then decays very slowly since it remains observed as a predominant species for several months for the three samples. The CTC intensity results from several contributions that occur simultaneously with different kinetic rates such as: (i) micropore molecule diffusion to an active site, (ii) ionization yield and rate leading to radical cation formation, (iii) radical cation stabilization since possible geminated recombination and high radical cation stability are factors that decrease or delay CTC formation, and (iv) CTC stabilization linked to electron compartmentalization.[1, 16] Fig. 9 represents the CTC amount formed in H-ZSM-5 and H-*BEA zeolite samples after $t$-stilbene contact for 300,600 and $1500 \mathrm{~h}$. On this time scale, the radical cation is no longer observed. It is worth noting that the maximum intensity of CTC is reached after $300 \mathrm{~h}$ for H-ZSM-5 while it is reached after about $1500 \mathrm{~h}$ for the H-*BEA samples. Furthermore, Fig. 9 shows that the CTC intensities are always higher in the H-*BEA samples compared to H-ZSM-5 when the maximum is obtained. The CTC is also better stabilized in $\mathrm{H}-* \mathrm{BEA}$ zeolite in which the signal decrease is very slow.

Thus, to illustrate the correlation between Brønsted site number and the reactivity of the adsorbed molecule, the maximum intensities obtained for the radical cation and/or the CTC were plotted as a function of Brønsted acid sites corresponding to the tetrahedral aluminum content for H-ZSM-5 and for H-*BEA zeolites (Fig. 10). By including the null contribution of silicalite-1, this graph shows that from a quantitative point of view, we get a similar behavior for the amounts of $t-\mathrm{St}^{+} \bullet$ and CTC in H-ZSM-5 zeolites. $t$-St radical cation and CTC intensities in H-ZSM-5 zeolite increase when the Brønsted acid site number increases. The evolution is fairly proportional and coherent with the $\mathrm{Si} / \mathrm{Al}$ framework ratio of the samples. A similar trend is also observed for the CTC stabilized in the channels of $\mathrm{H}-*$ BEA zeolites. As the $t$-St radical cation amount stabilized in *BEA zeolites is very low, its evolution versus Brønsted sites cannot be shown in Fig. 10.

Compared to the MFI samples, a significant amount of CTC is formed within *BEA whereas the Brønsted 
site concentration is lower than that in the MFI samples with the same Si/Al ratios. So, Brønsted acidity is not the unique parameter driving CTC formation and stabilization.

a. Adsorption step

Lewis site

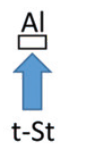

c1. Direct recombination Isolated Lewis site

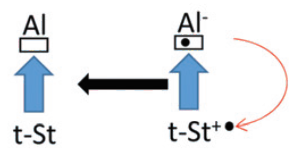

b. Radical cation formation

Lewis site

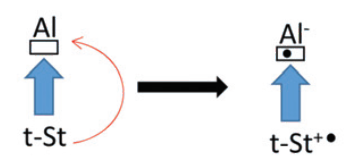

c2. Electron hopping

Strong Lewis site in vicinity

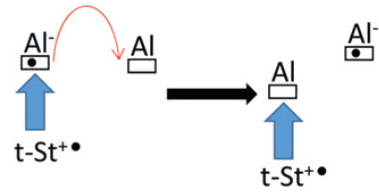

$\mathrm{t}-\mathrm{St}^{+} \bullet$

Al- c3. CTC formation

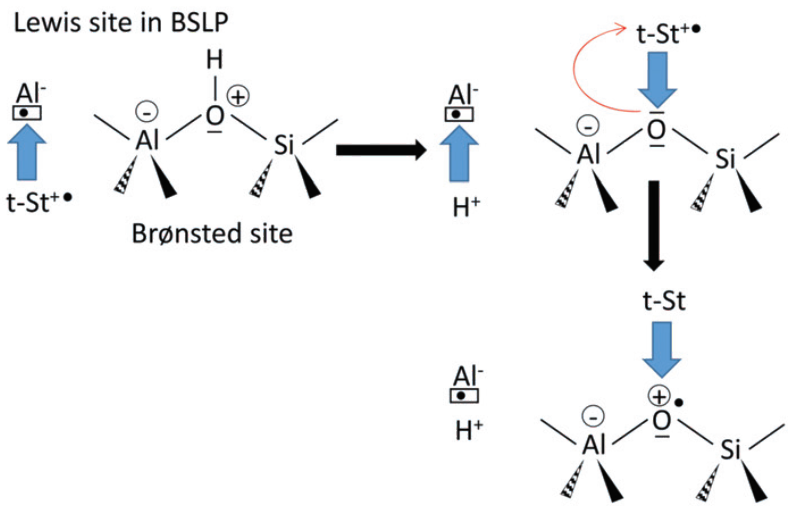

CTC

\section{d1. Electron hopping}

d2. Direct recombination

Strong Lewis site in BSLP vicinity

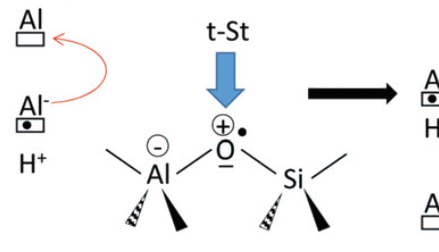

CTC

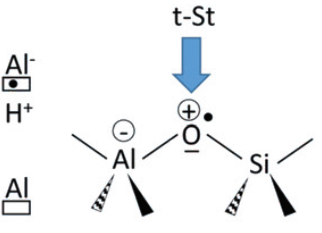

CTC

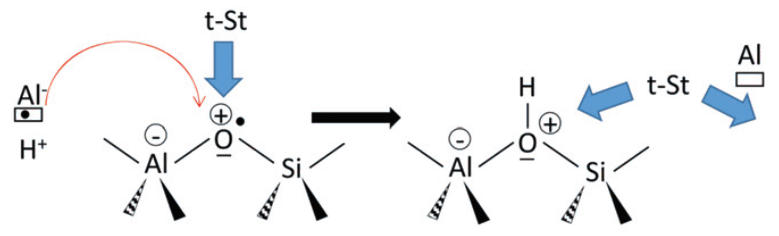

CTC

Fig. 11. Electronic transfer mechanism occuring after $t$-stilbene adsoprtion on H-ZSM-5 and *BEA-type zeolites.

In a previous paper, [18] we have shown that radical cation amount and its stability depend on the presence in the zeolite framework of strong Lewis acid sites in the vicinity of Brønsted sites named BSLPs. We have shown that the maximum radical amount is linked to the BSLP proportion with respect to the strong Lewis sites. Using the obtained results here, we are now able to explain more precisely the stabilization mechanism of the different separated charge states.

Radical cation formation occurs when a neutral $t$-St molecule is adsorbed on a Lewis site (Fig. 11a) and transfers an electron to the site (Fig. 11b). Then, we postulate that the fate of the $t$-stilbene radical cation depends on the environment of the Lewis site. Three evolution ways can be considered. If the Lewis site is isolated from other acid sites, direct and rapid recombination can occur (Fig. 11c1). If the Lewis site is in the vicinity of another stronger Lewis site, electron hopping may happen leading to radical cation stabilization (Fig. 11c2). This phenomenon has already been postulated in previous papers16 in order to explain separated charge stabilization. When the Lewis site forms with a Brønsted one a BSLP, the CTC is formed by ion exchange and electron transfer [18] (Fig. 11c3). In the case of *BEA zeolites, the proportion of Lewis sites involved in BSLPs must be higher than those in MFI zeolites because the radical cation is less stabilized in *BEA and the CTC amounts are much higher (Fig. 9). The CTC maximum intensity depends not only on the amount of radical cations formed but also 
on their ability to be stabilized by the zeolite framework. Stabilisation requires an electron hopping phenomenon that needs strong Lewis sites in the vicinity of the BSLP (Fig. 11d1); otherwise, geminated recombination occurs between the electronic hole generated at the Brønsted site and the electron located on the Lewis site of the BSLP (Fig. 11d2). Besides, the lower confinement in the larger pores of *BEA can also have a dramatic effect on the diffusion process of the adsorbed species and consequently on the reaction kinetics, especially on the studied time scale (several weeks or months).

Thus, Lewis acid sites play an important role in the charge transfer processes. Our results demonstrate that the maximum CTC intensity can be linked to the zeolite $\mathrm{Al}^{(\mathrm{VI})}$ content determined by ${ }^{27} \mathrm{Al}$ MAS NMR as shown in Fig. 12A showing the increase of the CTC maximum spectral concentration with the increase of the EFAL amount.
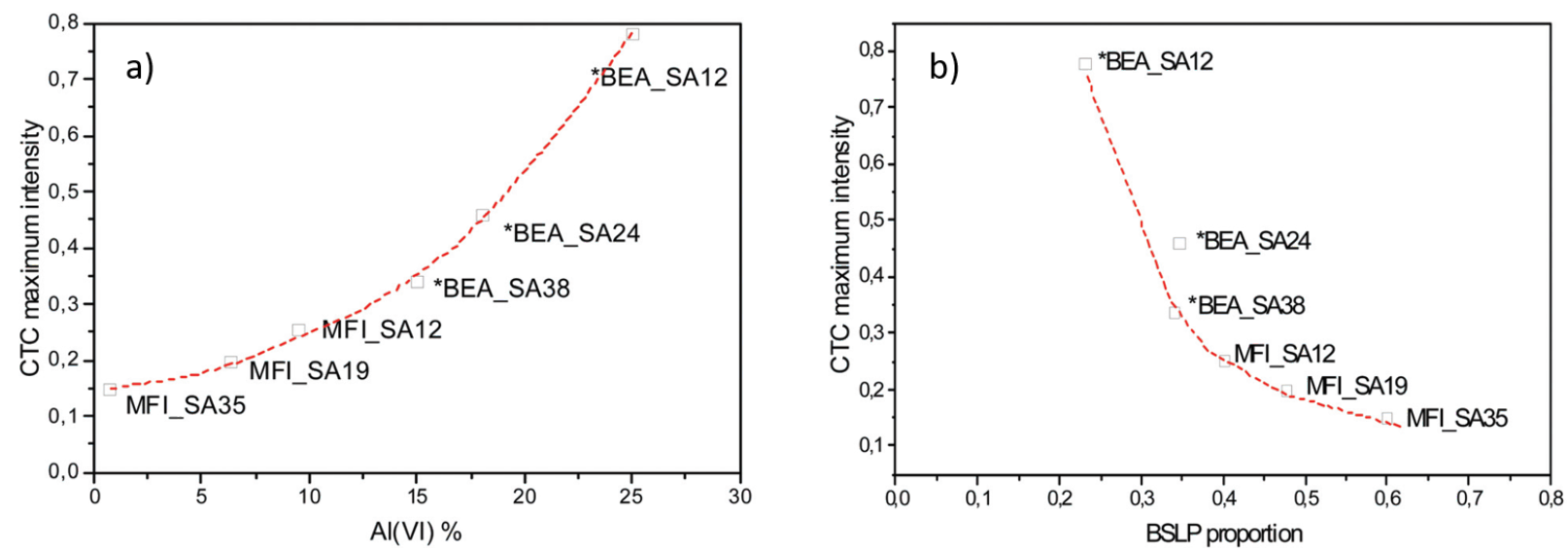

Fig. 12. (a) Maximum CTC intensity versus $\mathrm{Al}^{(\mathrm{VI})}$ for $\mathrm{H}-\mathrm{ZSM}-5$ and $* \mathrm{BEA}$-type zeolites. (b) maximum CTC intensity versus BSLP proportion for H-ZSM-5 and *BEA-type zeolites.

EFAL species are representative of Lewis sites and these sites are necessary for the radical cation formation and CTC formation. Moreover, the CTC maximum amount also increases with the BSLP amount, which can be represented by the area of the iminium IR absorption band (not shown). However, according to the proposed mechanism, the strength and the distribution of the acid sites and especially the Lewis ones play an important role in radical cation and CTC stabilization. Fig. 12B shows the BSLP proportion with respect to the strong Lewis sites calculated from the FTIR spectra of adsorbed pyridine as the ratio between the area of the IR band at $1462 \mathrm{~cm}^{-1}$ (iminium ion) and the area of the whole absorption band in the $1475-1430 \mathrm{~cm}^{-1}$ region for pyridine desorption at $4501 \mathrm{C}$. When the BSLP proportion increases, the maximum CTC amount decreases significantly. This result indicates that even if BSLPs are necessary for CTC formation, an important proportion of these sites with respect to strong Lewis sites has a negative effect on CTC stabilization. So, if there are not enough strong Lewis sites in the vicinity of a BSLP, the electron-hole pair recombines more rapidly (Fig. 11d1 and d2) and the CTC amount decreases.

\section{CONCLUSION}

A decrease in the $\mathrm{Si} / \mathrm{Al}$ ratio results in the addition of aluminium within the zeolitic structure and induces a dilation of the framework. Aluminium is added inside and outside the structure. Acidity analysis showed that the increase in the aluminium content leads to an almost linear increase in the total number of Brønsted and Lewis acidic sites, but leads to a quasi linear decrease in the proportion of strong acidic sites. In this context, having a thorough knowledge of the quantity and distribution of acidic sites in ZSM-5 and *BEA zeolites, we investigated the influence of the $\mathrm{Si} / \mathrm{Al}$ ratio on the physico-chemical properties of zeolites to determine the effect of their modification on charge transfer occuring after adsorption and ionization of $t$-stilbene as a probe molecule. The reaction mechanisms are identical for both types of zeolite with initial spontaneous ionization and formation of 
radical cations and subsequent electron transfer to induce the formation of a charge transfer complex (CTC). The ionization rate and the maximum ionization yield increase with the Al content for ZSM-5 and *BEA. However, the kinetics of electron transfer to form the CTC is much faster in *BEA where the radical is barely detected. The time to reach the maximum CTC intensity is 12-15 days for ZSM-5 and about 2 months for *BEA. Different diffusion processes, ionization yields and rates, and stabilization of charge separated states have to be taken into account to explain the different behaviours between ZSM-5 and *BEA zeolites. Indeed, even if the internal electrostatic field within acidic ZSM-5 and *BEA is high enough to induce spontaneous ionization of $t$-stilbene in both topologies, the stronger confinement effect in ZSM-5 must be considered to explain the higher stabilization of the radical cation in the narrower pores of ZSM-5. The radical cation is clearly observed in ZSM-5 (10-MRs zeolite) while it is hardly or not detected in *BEA (12-MRs zeolite) for similar Si/Al ratios. In the large pore *BEA, the intensity of the local electrostatic field at the sorption site is not strong enough to stabilize the radical cation by non-covalent interactions. The subsequent electron transfers are then much faster to form long lived charge transfer complexes whose stabilization is explained by the principle of compartmentalization.

A clear correlation is shown between the maximum spectral concentrations of the radical cation and of the CTC and the Brønsted acidity. Nevertheless, even if the intensity increases with the Brønsted acidity, higher intensities are observed in *BEA where the number of Brønsted sites is less indicating that Brønsted acidity is not the only parameter involved in the formation and stabilization of the CTC.

Thus, using our recent work in which we have demonstrated that the amount of radical cations and their stability are intimately associated with Brønsted-strong Lewis pairs (BSLPs), we correlate this parameter here and more particularly the environment of Lewis acid sites to explain the electron transfers and charge stabilization that occur after the initial ionization. For ZSM-5 and *BEA zeolites, BSLPs increase with the concentration of Brønsted acid sites and $\mathrm{Al}^{(\mathrm{VI})}$, which is directly associated with Lewis acidity. Nevertheless, it appears that the formation of a BSLP requires more $\mathrm{Al}^{(\mathrm{VI})}$ ) in *BEA than in ZSM-5. In addition, it has been shown that the total Lewis and Brønsted acid strength decreases when the amount of $\mathrm{Al}^{(\mathrm{VI})}$, i.e. EFAL, increases. The role of Lewis acid sites is demonstrated and is a key factor in increasing the CTC amount. These Lewis sites are necessary for both initial ionization and CTC formation. The strength and distribution of acid sites are also of high importance in the charge separated state stabilization. However, we also show evidence that even if the BSLP favors electron transfer and stabilization, too large a proportion of these BSLP sites compared to Lewis sites has the opposite effect of disfavoring CTC formation and/or stabilization.

\section{CONFLICTS OF INTEREST}

There are no conflicts to declare.

\section{ACKNOWLEDGMENTS}

This work was supported by the Agence Nationale de la Recherche (ANR), project HIZEOTREL (ANR-14CE08-0012-01). T. Crémoux is grateful for financial support (PhD grant).

\section{REFERENCES}

(1) A. Moissette, M. Hureau, H. Vezin and R. F. Lobo, in Chemistry of silica and zeolite-based materials, ed. A. Douhal and M. Anpo, Elsevier, 2019, vol. 2, ch. 14 - Electron transfers under confinement in channel-type zeolites, pp. 249-271.

(2) M. Hureau, A. Moissette, H. Vezin, C. Brémard and M. Orio, J. Phys. Chem. C, 2012, 116, 1812-1825.

(3) H. García and H. D. Roth, Chem. Rev., 2002, 102, 3947-4008.

(4) D. J. Cardin, Adv. Mater., 2002, 14, 553-563.

(5) A. Bhan and E. Iglesia, Acc. Chem. Res., 2008, 41, 559-567.

(6) L. Li, X.-S. Zhou, G.-D. Li, X.-L. Pan and J.-S. Chen, Angew. Chem., Int. Ed., 2009, 48, 6678-6682. 
(7) N. Kosinov, A. S. G. Wijpkema, E. Uslamin, R. Rohling, F. J. A. G. Coumans, B. Mezari, A. Parastaev, A. S. Poryvaev, M. V. Fedin, E. A. Pidko and E. J. M. Hensen, Angew. Chem., Int. Ed., 2018, 57, 10161020.

(8) M. J. Nash, A. M. Shough, D. W. Fickel, D. J. Doren and R. F. Lobo, J. Am. Chem. Soc., 2008, 130, 2460-2462.

(9) A. Moissette, S. Marquis, I. Gener and C. Brémard, Phys. Chem. Chem. Phys., 2002, 4, 5690-5696.

(10) S. Marquis, A. Moissette, H. Vezin and C. Brémard, C. R. Chim., 2005, 8, 419-440.

(11) M. Hureau, A. Moissette, S. Marquis, C. Brémard and H. Vezin, Phys. Chem. Chem. Phys., 2009, 11, 6299-6307.

(12) S. Marquis, A. Moissette, H. Vezin and C. Brémard, J. Phys. Chem. B, 2005, 109, 3723-3726.

(13) M. A. O’Neill, F. L. Cozens and N. P. Schepp, J. Phys. Chem. B, 2001, 105, 12746-12758.

(14) K. B. Yoon, Chem. Rev., 1993, 93, 321-339.

(15) S. Hashimoto, J. Photochem. Photobiol., C, 2003, 4, 19-49.

(16) M. Hureau, A. Moissette, H. Vezin, C. Brémard and M. Orio, J. Phys. Chem. C, 2012, 116, 1812-1825.

(17) M. Hureau, A. Moissette, J. Gaillard and C. Brémard, Photochem. Photobiol. Sci., 2012, 11, 1515-1519.

(18) T. Crémoux, I. Batonneau-Gener, A. Moissette, J.-L. Paillaud, M. Hureau, E. Ligner, C. Morais, S. Laforge, C. Marichal and H. Nouali, Phys. Chem. Chem. Phys., 2018, 20, 26903-26917.

(19) J.-L. Guth, H. Kessler and R. Wey, in New Developments in Zeolite Science and Technology, ed. Y. Murakami, A. Iijima and J. Ward, Elsevier, 1986, vol. 28, pp. 121-128.

(20) M. Ali, B. Brisdon and W. Thomas, Appl. Catal., A, 2003, 252, 149-162.

(21) H. Jon, B. Lu, Y. Oumi, K. Itabashi and T. Sano, Microporous Mesoporous Mater., 2006, 89, 88-95.

(22) M. Jaroniec, M. Kruk and J. P. Olivier, Langmuir, 1999, 15, 5410-5413.

(23) B. Chiche, F. Fajula and E. Garrone, J. Catal., 1994, 146, 460-467.

(24) D. Massiot, F. Fayon, M. Capron, I. King, S. Le Calvé, B. Alonso, J.-O. Durand, B. Bujoli, Z. Gan and G. Hoatson, Magn. Reson. Chem., 2002, 40, 70-76.

(25) M. Thommes, K. Kaneko, V. Neimark Alexander, P. Olivier James, F. Rodriguez-Reinoso, J. Rouquerol and S. W. Sing Kenneth, Pure Appl. Chem., 2015, 87, 1051-1069.

(26) In, Multinuclear Solid-State NMR of Inorganic Materials, ed. K. J. MacKenzie and M. E. Smith, Pergamon, 2002, vol. 6, ch. 4 - ${ }^{29}$ Si NMR, pp. 201-268.

(27) S. Sklenak, J. Dědeček, C. Li, B. Wichterlová, V. Gábová, M. Sierka and J. Sauer, Phys. Chem. Chem. Phys., 2009, 11, 1237-1247.

(28) C. A. Fyfe, J. H. O'Brien and H. Strobl, Nature, 1987, 326, 281-283.

(29) J. Stelzer, M. Paulus, M. Hunger and J. Weitkamp, Microporous Mesoporous Mater., 1998, 22, 1-8.

(30) S. M. Maier, A. Jentys and J. A. Lercher, J. Phys. Chem. C, 2011, 115, 8005-8013.

(31) S. Almutairi, B. Mezari, G. Filonenko, P. Magusin, E. Pidko and E. Hensen, ChemCatChem, 2013, 5, 452-466.

(32) In, Multinuclear Solid-State NMR of Inorganic Materials, ed. K. J. MacKenzie and M. E. Smith, Pergamon, 2002, vol. 6, ch. $5-{ }^{27} \mathrm{Al}$ NMR, pp. 271-330.

(33) J. A. van Bokhoven, D. C. Koningsberger, P. Kunkeler, H. van Bekkum and A. P. M. Kentgens, J. Am. Chem. Soc., 2000, 122, 12842-12847. 
(34) J. P. Marques, I. Gener, P. Ayrault, J. C. Bordado, J. M. Lopes, F. R. Ribeiro and M. Guisnet, C. R. Chim., 2005, 8, 399-410.

(35) M. S. Holm, S. Svelle, F. Joensen, P. Beato, C. H. Christensen, S. Bordiga and M. Bjørgen, Appl. Catal., A, 2009, 356, 23-30.

(36) I. Kiricsi, C. Flego, G. Pazzuconi, W. O. J. Parker, R. Millini, C. Perego and G. Bellussi, J. Phys. Chem., 1994, 98, 4627-4634.

(37) A. Vimont, F. Thibault-Starzyk and J. C. Lavalley, J. Phys. Chem. B, 2000, 104, 286-291.

(38) J. Groen, L. Peffer, J. Moulijn and J. Pérez-Ramırez, Colloids Surf., A, 2004, 241, 53-58.

(39) A. Zecchina, S. Bordiga, G. Spoto, D. Scarano, G. Petrini, G. Leofanti, M. Padovan and C. O. Areàn, J. Chem. Soc., Faraday Trans., 1992, 88, 2959-2969.

(40) J. P. Marques, I. Gener, P. Ayrault, J. C. Bordado, J. M. Lopes, F. R. Ribeiro and M. Guisnet, Microporous Mesoporous Mater., 2003, 60, 251-262.

(41) O. Kresnawahjuesa, R. Gorte, D. Oliveira and L. Lau, Catal. Lett., 2002, 82, 155-160.

(42) A. Moissette, R. F. Lobo, H. Vezin, K. A. Al-Majnouni and C. Brémard, J. Phys. Chem. C, 2010, 114, 10280-10290. 